\title{
Humor Styles in Indian University Students
}

\section{Neelam Arjan Hiranandani* and Serena Ru Bing Yue}

Department of Applied Social Studies, City University of Hong Kong, Y7422 AC1, 81 Chee Avenue, Kowloon Tong, Hong Kong

\section{Abstract}

This study examined the relationship between humor styles, self-esteem and humor perception in India. The Humor Styles Questionnaire and the Rosenberg Self-esteem scale were used to survey 102 university students in India. Participants were also required to rate on importance of humor and their own level of humor. Results indicated that Indian university students tend to use more adaptive humor styles (affiliative humor and self-enhancing humor) than maladaptive humor styles (aggressive humor and self-defeating humor). The findings also showed that the more adaptive humor styles Indian students used, the better they felt about themselves. The humor styles, self-esteem and humor perception provide useful suggestions for future interventions. The present study needs to be interpreted with caution as it is only based on university students.

\section{Introduction}

Humor is a universal practice and people of different societies perceive and use humor differently $[1,2]$. Based on the standards existing in the social and cultural setting, people make judgments of attributional characteristics [3,4]. For example, certain humor [5] styles could account for possibilities for inter-relations [6]. Humor used in social interactions can be divided into 2 groups (adaptive and maladaptive humor) and further differentiated into 4 humor styles [7]. Humor styles can be divided into adaptive humor that facilitates relationships and lessens interpersonal tensions, and maladaptive humor that is unhealthy and harmful to either themselves or others by disparagement $[7,8]$. Adaptive humor includes: (1) affiliative humor that promotes and improves interpersonal relationships, feelings of well-being and reduces conflicts; and (2) self-enhancing humor that enhances and protects oneself by maintaining a realistic perspective on life [7]. Maladaptive humor includes: (3) aggressive humor means to criticize or manipulate others and serves a potentially negative impact towards others; and (4) self-defeating humor, inappropriately amuses humor at the cost of oneself [7]. Thus, this study examines the relationship between humor styles (adaptive or maladaptive humor styles), self-esteem and humor perception in India society.

Humor is found to help people with coping with stress effectively, enjoy life better, experience less negative emotions and have healthier interpersonal relationships [9-11]. Previous studies also showed that healthy humor was positively related with self-esteem $[7,12]$. As such, this study aims to investigate whether humor can influence one's selfesteem level in Indian university students (for example, the higher selfesteem one has, the higher use of affiliative humor and self-enhancing humor they report). Also, as described above, not all humor styles are beneficial (e.g., maladaptive humor styles) [7], one may have low selfesteem due to lack of confidence caused by use of aggressive humor in situations that direct towards one's weight [13]. Hence, humor may diminish human relations and reduce communicative atmosphere.

As to humor perception, valuation of humor and evaluation of self humor were found to be important for humor use [2]. For example, Chinese and Taiwanese university students valued humor less than their counterparts in the West $[14,15]$. So individual and cultural differences exist in humor appreciation as well as in humor use as a coping mechanism [11]. After all, the better the person can use and interpret humor, the more competent he is in social situations [11].

Studies of humor styles and humor perception are rare and sporadic in India. Of the few English articles we could find, it argued that the
Indian term of mazaak was taken as an alternative word for humor in English and that people engaged in mazaak for mazaa (enjoyment and thrill) [6]. Ramaswami [6] explored the proletarian masculinity and mazaak, reporting that industrial workers in Delhi tended to use gandaa mazaak (vulgar humor) to cope with the hardship at work. Besides, male students scored higher than females on the sense of humor [16].

Given that there have not been any empirical studies that examined the humor styles in Indian society, we conducted the present study to fill in the gap and hypothesizes that: (1) Indian university students would use adaptive humor styles (affiliative humor and self-enhancing humor) more than maladaptive humor styles (aggressive humor and self-defeating humor) (Hypothesis 1); (2) Indian males would value humor more than females and consider themselves more humorous than females (Hypothesis 2); and (3) self esteem would be positively correlated with adaptive humor styles and be negatively correlated with maladaptive humor styles (Hypothesis 3).

\section{Method \\ Participants}

The participants in the present study were sampled from universities in India. 102 undergraduate students (61 males; 41 females) were recruited randomly from University of Mumbai and University of Calcutta. The participants' age ranged from 18 to 25 years $(M=$ $21.06, S D=1.69)$. The participants were recruited from the university campus' canteens randomly and they belonged to journalism, education, social sciences, engineering, law, and business faculties.

\section{Measures}

The questionnaire included the Humor styles Questionnaire and the Rosenberg Self-esteem scale and also required the participants to rate the importance of humor and their self humor.

"Corresponding Author: Neelam Arjan Hiranandani, Department of Applied Social Studies, City University of Hong Kong, Y7422 AC1, 81 Chee Avenue, Kowloon Tong, Hong Kong SAR China; E-mail: nhiranand2@cityu.edu.hk

Citation: Hiranandani NA, Bing Yue SR (2015) Humor Styles in Indian University Students. Int J Psychol Behav Anal 1: 104. doi: http://dx.doi.org/10.15344/2455$3867 / 2015 / 104$

Copyright: (C) 2015 Hiranandani et al. This is an open-access article distributed under the terms of the Creative Commons Attribution License, which permits unrestricted use, distribution, and reproduction in any medium, provided the original author and source are credited. 
The Humor Styles Questionnaire (HSQ,[7]) measures the four humor styles: affiliative humor (e.g., "I laugh and joke a lot with my friends"), self-enhancing humor (e.g., "My humorous outlook on life keeps me from getting overly upset or depressed about things"), aggressive humor (e.g., "If someone makes a mistake, I will often tease them about it"), and self-defeating humor (e.g., "I let people laugh at me or make fun at my expense more than I should"). It comprised of four 8 -item scales and rating on a 7-point Likert scale sub-ranging from totally disagree to totally agree. In the present sample, the Cronbach's Alpha of affiliative, self-enhancing, aggressive, and selfdefeating humor was $.74, .64, .50$, and .58 , suggesting that the scale is reliable to use as an instrument.

The Rosenberg Self-esteem scale (RSES, [17]) measures how well one feel about himself. It consisted of 10 general statements about the self (e.g., "On the whole, I am satisfied with myself) in which participants are required to rate the items on a 4-point Likert scale ranging from strongly agree to strongly disagree. This scale has been widely used and has shown good reliability and validity $[17,18]$. The Cronbach's Alpha $(\alpha=.74)$ reflected the high reliability for the use in this scale in this sample.

Finally, all participants were required to rate on a 10-point Likert scale (1=lowest; $10=$ highest): (1) the importance of humor to them ("How important is humor to you?"), and (2) their own level of humor ("Rate your own level of humor/self humor").

\section{Procedures}

The participants were invited to complete a questionnaire on a voluntary basis during lecture or tutorial time. The questionnaire administered to all participants was in English as all the participants use English as the language while in class and were competent using the language. The completion of the questionnaire took approximately 15 to 20 minutes. Lastly, the data collected were then entered in SPSS 20 and the mean differences and correlations were conducted through independent t-tests, ANOVA and bivariate correlation.

\section{Results}

In regard to humor styles, the outcome notes with satisfaction that Indian university students used adaptive humor styles significantly more than maladaptive humor styles and hypothesis 1 was supported (Table 1). Therefore, this study's results validate previous findings, which emphasized that collectivistic cultures use the affiliative, and self-enhancing humor styles more than the aggressive and selfdefeating humor styles $(\mathrm{F}(3,303)=49.33, \mathrm{p}<.001 ;[11,19]$.

For the humor perception, Indian males evaluated their humor level significantly higher than Indian females $(\mathrm{t}=2.48, \mathrm{p}=.015)$. Females valued the importance of humor more than males; however, no significant results were reported, offering partial support to hypothesis 2 (Table 2 ).

Table 3 provides an overview of the correlation between humor styles, self-esteem and humor perception. Affiliative humor was positively correlated with self-enhancing humor $(r=.42, p=.000)$. Self-defeating humor was positively correlated with aggressive humor $(r=.25, p=$ .011). Partially supporting hypothesis 3 , self-esteem was positively correlated with adaptive humor styles (affiliative humor, $r=.35, p=$ .000 ; self-enhancing humor, $r=.33, p=.001)$ and negatively correlated with self-defeating humor $(r=-.22, p=.03)$. Moreover, importance of humor was positively correlated with adaptive humor (affiliative humor, $r=.35, p=.000$; self-enhancing humor, $(r=.25, p=.012)$

\begin{tabular}{|l|l|l|l|l|l|l|l|l|l|l|}
\hline & \multicolumn{3}{l|}{ Affiliative Humor } & \multicolumn{3}{l|}{ Self-enhancing Humor } & \multicolumn{3}{l|}{ Aggressive Humor } & \multicolumn{3}{l|}{ Self-defeating Humor } & \\
\hline & $\mathrm{M}$ & $\mathrm{SD}$ & $\mathrm{M}$ & $\mathrm{SD}$ & $\mathrm{M}$ & SD & $\mathrm{M}$ & SD & F-value \\
\hline $\begin{array}{l}\text { Indian } \\
(\mathrm{N}=102)\end{array}$ & 39.75 & 8.92 & 36.54 & 7.99 & 28.91 & 6.83 & 30.52 & 7.43 & $49.33^{* * *}$ \\
\hline
\end{tabular}

Table 1: Comparison in the use of humor styles among the Indian university students.

\begin{tabular}{|l|l|l|l|l|l|}
\hline & Males $(\mathrm{n}=61)$ & Females $(\mathrm{n}=41)$ & & & \\
\hline & $\mathrm{M}$ & SD & M & SD & t-value \\
\hline Importance of Humor & 7.72 & 2.54 & 8.29 & 1.69 & -1.26 \\
\hline Self-Humor & 7.41 & 1.80 & 6.59 & 1.38 & $2.48^{*}$ \\
\hline
\end{tabular}

Table 2: Means and Standard Deviations for Rating of Importance of Humor and of Self humor in Males and Females.

\begin{tabular}{|l|l|l|l|l|l|l|l|}
\hline & Affiliative humor & Self-enhancing humor & Aggressive humor & Self-defeating humor & Self-esteem & Importance of humor & Self \\
\hline humor & & & & & & & \\
\hline Affiliative Humor & - & - & - & - & - & - & \\
\hline Self-Enhancing Humor & $.42^{* * *}$ & - & - & - & - & - & - \\
\hline Aggressive Humor & -.04 & .07 & - & - & - & - & - \\
\hline Self-Defeating Humor & -.13 & .19 & $.25^{*}$ & - & - & - & - \\
\hline Self-Esteem & $.35^{* * *}$ & $.33^{* * *}$ & -.110 & $-.22^{*}$ & - & - & - \\
\hline Importance of humor & $.35^{* *}$ & $.25^{*}$ & -.04 & .06 & $.27^{* *}$ & - & - \\
\hline Self humor & .11 & $.22^{*}$ & .12 & $.21^{*}$ & $.25^{* *}$ & $.43^{* * *}$ & - \\
\hline
\end{tabular}

Table 3: Correlation between Humor styles, Self-esteem, and Humor perception.

Note: Correlation is significant if ${ }^{*} \mathrm{p}<.05 ;{ }^{* *} \mathrm{p}<.01 ;{ }^{* * *} \mathrm{p}<.001$ 
and self-esteem $(r=.27, p=.007)$. Self humor was positively correlated with self-enhancing humor $(r=.22, p=.029)$, self-defeating humor $(r$ $=.21, p=.03)$, self-esteem $(r=.25, p=.01)$ and importance of humor $(r=.43, p=.000)$.

\section{Discussion}

This is the first study to examine humor styles in India. Very few studies on humor styles have included an Indian sample that may help to explain the themes in Indian psychology, personality and communication.

This study showed that Indian students used adaptive humor styles more than maladaptive humor styles. This reflects that Indian students tend to use mazaak (humor) to enhance relationships [6]. This could be attributed to that collectivism is emphasized in Indian culture [20-23], as such adaptive humor promotes reciprocity and interdependence among people. This also shows that humor styles matters for interpersonal relationships and communications, that is, affiliative and self-enhancing humor enhance social harmony and selfesteem while aggressive and self-defeating humor do otherwise[7,11].

Similarly, males considered themselves to be more humorous than females. This is in line with previous studies that males felt more competent of humor use than females [11,24]. Moreover, valuation of humor was positively correlated with adaptive humor and self-esteem. This implies that the more students valued humor, the more adaptive humor styles they used, and the better they felt about themselves $[25,26]$. This also reflects an important factor in determining who we are and how we think of ourselves [11,27].

It was convincing to note that for the present Indian sample, self-esteem is positively correlated with adaptive humor styles and is negatively correlated with self-defeating humor for Indian students. This echoes previous findings that use of adaptive humor styles enhances self-esteem, peer acceptance, group identity and cohesiveness $[8,25]$.

In short, humor matters in Indian societies. Maslow argued that humor is a characteristic of good health [28]. Self-actualizing people acquire non-aggressive humor styles to cope with stress [28], and people who score high on humor measures tend to have higher selfesteem [25], not to mention that this was also found in the present study.

\section{Limitations and Suggestions for Future Studies}

Although this study demonstrated profound results in Indian humor styles, there were a few limitations to note. Firstly, this study reported that Indian students' use of adaptive humor styles (affiliative and self-enhancing humor) was most preferred; the self-report measure may limit participants' responses. Future studies ought to include qualitative measures to determine the extent to which these findings of Indian humor are consistent. Secondly, longitudinal studies in the future can help to determine the contribution of humor styles to other factors contributing to psychological well-being, such as, emotional well-being, subjective happiness and resilience. This study considered the Indian university students' use humor styles as their preferred social interaction styles and social influence of significant others. Lastly, as this is a pioneering study, the value of this study lies in that it is the pioneering study ever conducted in India. It will provide the initial findings for later verification and discussion. Future studies should consider collecting more data from people from different walks of life to validate this study's findings.

\section{References}

1. Martin RA (2007) The Psychology of Humor: An Integrative approach. Burlington. MA: Elsevier Academic Press.

2. Yue XD (2010) Exploration of Chinese humor: historical review, empirical findings, and critical reflections. Humor 23: 403-420.

3. Csikszentmihalyi M (1988) Society, culture, and person: a system view of creativity. In Sternberg RJ (Ed) The nature of creativity. New York: Cambridge University Press. 325-339.

4. Ludwig AM (1992) Culture and creativity. Am J Psychother 46: 454-469.

5. Maslow A (1968) Toward a Psychology of Being. New York: Van Nostrand.

6. Ramaswami S (2006) Masculinity, Respect, and the Tragic: Themes of Proletarian Humor in Contemporary Industrial Delhi. Int Rev Soc Hist 51: 203-227.

7. Martin RA, Puhlik-Doris P, Larsen G, Gray J, Weir K (2003) Individual differences in uses of humor and their relation to psychological well-being: Development of the humor styles questionnaire. J Res Pers 37: 48-75.

8. Klein D, Kuiper N (2006) Humor styles, peer relationships, and bullying in middle childhood. Humor 19: 383-404.

9. Cheung CK, Yue XD (2012) Sojourn students' humor styles as buffers to achieve resilience. Int J Intercult Rel 36: 353-364.

10. Kuiper N, Olinger J (1998) Humor and mental health. In H. Friedman (Ed.), Encyclopedia of mental health. 2: 445-457.

11. Yue XD, Hao X, Goldman GL (2010) Humor styles, dispositional optimism and mental health: a study among 800 undergraduates in Hong Kong and Mainland China. J Psychol Chinese Soc 11: 173-188.

12. Kuiper NA, Grimshaw M, Leite C, Kirsh G (2004) Humor is not always the best medicine: Specific components of sense of humor and psychological well-being. Humor 17: 135-168.

13. Hoffmeister K, Teige-Mocigemba S, Blechert J, Klauer KC, Tuschen-Caffier $B$ (2010) Is implicit self-esteem linked to shape and weight concerns in restrained and unrestrained eaters? J Behav Ther Exp Psychiatry 41: 3138.

14. Liao CC (2001) Taiwanese perceptions of humor: A sociolinguistic perspective. Taipei: Crane.

15. Chen G, Martin R (2007) A comparison of humor styles, coping humor, and mental health between Chinese and Canadian university students. Humor 20: $215-234$

16. Madhan B, Barik AK, Patil R, Gayathri H, Reddy MS (2013) Sense of humor and its association with psychological disturbances among dental students in India. J Dent Educ 77: 1338-1344.

17. Rosenberg M (1965) Society and the adolescent self-image. Princeton, NJ: Princeton University Press.

18. Greenberger E, Chen C, Dmitrieva J, Farruggia SP (2003) Item-wording and the dimensionality of the Rosenberg self-esteem scale: Do they matter? Personality and Individual Differences, 35: 1241-1254.

19. Yue XD, Hao X, Lan L, Yan F (2006) Humor and Youth Empowerment: A Self-Cultivation Approach. Paper Presented at the 2nd International Conference on Youth Empowerment, City University of Hong Kong, Hong Kong, China: June 5-8, 2006.

20. Tamis-LeMonda CS, Hughes D, Yoshikawa H, Kalman RK, Niwa E and et al. (2008) Parents' Goals for Children: The Dynamic Coexistence of Individualism and Collectivism in Cultures and Individuals. Social Dev 17: 183-209.

21. Sinha JB, Vohra N, Singhal S, Sinha RBN, Ushashree S (2002) Normative predictions of collectivist-individualist intentions and behaviour of Indians. Int J Psycho 37: 309-319. 
Citation: Hiranandani NA, Bing Yue SR (2015) Humor Styles in Indian University Students. Int J Psychol Behav Anal 1: 104. doi: http://dx.doi.org/10.15344/2455$3867 / 2015 / 104$

22. Bond MH (1996) Handbook of Chinese psychology. New York Oxford University Press.

23. Ho DYF (1995) Selfhood and identity in Confucianism, Taoism, Buddhism and Hindism: contrasts with the West. J Theo Soc Behav 25: 115-139.

24. Yue XD (2011) The Chinese ambivalence to humor: Views from University students in Hong Kong and China. Humor: Int J Humor Res 24: 463-480.

25. Kuiper NA, Martin RA (1993) Humor and self-concept. Humor: Int J Humor Res 6: 251-270.

26. Yue XD, Liu KW, Jiang F, Hiranandani NA (2014) Humor styles, selfesteem, and subjective happiness. Psychol Rep 115: 517-525.

27. Sahoo FM, Mohapatra L (2013) Psychological well-being in professional groups. J Indian Acad App Psychol 35: 211-217.

28. Veale T., Feyaerts, K., and Brône G. (2006). The Cognitive Mechanisms of Adversarial Humor. Humor 19: 305-338. 